\title{
Inequality in child undernutrition among urban population in India: a decomposition analysis
}

\author{
S. K. Singh ${ }^{1}$ (D) Shobhit Srivastava ${ }^{*^{*}}$ (D) and Shekhar Chauhan²(D)
}

\begin{abstract}
Background: With increasing urbanization in India, child growth among urban poor has emerged as a paramount public health concern amidst the continuously growing slum population and deteriorating quality of life. This study analyses child undernutrition among urban poor and non-poor and decomposes the contribution of various factors influencing socio-economic inequality. This paper uses data from two recent rounds of National Family Health Survey (NFHS-3\&4) conducted during 2005-06 and 2015-16.

Methods: The concentration index (Cl) and the concentration curve (CC) measure socio-economic inequality in child growth in terms of stunting, wasting, and underweight. Wagstaff decomposition further analyses key contributors in $\mathrm{Cl}$ by segregating significant covariates into five groups-mother's factor, health-seeking factors, environmental factors, child factors, and socio-economic factors.
\end{abstract}

Results: The prevalence of child undernutrition was more pronounced among children from poor socio-economic strata. The concentration index decreased for stunting $(-0.186$ to -0.156$)$, underweight $(-0.213$ to -0.162$)$ and wasting ( -0.116 to -0.045$)$ from 2005 to 06 to 2015-16 respectively. The steepness in growth was more among urban poor than among urban non-poor in every age interval. Maternal education contributed about 19\%, 29\%, and 33\% to the inequality in stunting, underweight and wasting, respectively during 2005-06. During 2005-06 as well as 2015-16, maternal factors (specifically mother's education) were the highest contributory factors in explaining rich-poor inequality in stunting as well as underweight. More than $85 \%$ of the economic inequality in stunting, underweight, and wasting among urban children were explained by maternal factors, environmental factors, and health-seeking factors.

Conclusion: All the nutrition-specific and nutrition-sensitive interventions in urban areas should be prioritized, focusing on urban poor, who are often clustered in low-income slums. Rich-poor inequality in child growth calls out for integration and convergence of nutrition interventions with policy interventions aimed at poverty reduction. There is also a need to expand the scope of the Integrated Child Development Services (ICDS) program to provide mass education regarding nutrition and health by making provisions of home visits of workers primarily focusing on pregnant and lactating mothers.

Keywords: Underweight, Stunting, Wasting, Economic inequality, India

\footnotetext{
*Correspondence: shobhitsrivastava889@gmail.com

'Department of Mathematical Demography and Statistics, International Institute for Population Sciences, Mumbai, Maharashtra 400088, India

Full list of author information is available at the end of the article
}

(c) The Author(s). 2020 Open Access This article is licensed under a Creative Commons Attribution 4.0 International License, which permits use, sharing, adaptation, distribution and reproduction in any medium or format, as long as you give appropriate credit to the original author(s) and the source, provide a link to the Creative Commons licence, and indicate if changes were made. The images or other third party material in this article are included in the article's Creative Commons licence, unless indicated otherwise in a credit line to the material. If material is not included in the article's Creative Commons licence and your intended use is not permitted by statutory regulation or exceeds the permitted use, you will need to obtain permission directly from the copyright holder. To view a copy of this licence, visit http://creativecommons.org/licenses/by/4.0/. The Creative Commons Public Domain Dedication waiver (http://creativecommons.org/publicdomain/zero/1.0/) applies to the data made available in this article, unless otherwise stated in a credit line to the data. 


\section{Background}

The rapid increase in the urban population due to urbanization in the last one decade has contributed to the urban poverty in India [47]. It is manifested in the form of inadequate provision of housing and shelter, water, sanitation, health, education, social security, livelihoods, and food security along with the special needs of vulnerable groups like women, and children [13]. The health of urban children as measured with malnutrition in the existing context of urbanization, has become an important issue in India [26]. Malnutrition among children under age five is a paramount public health concern in many developing countries, and India is no exception [33].

Child under-nutrition is expressed in different forms, including stunting (->2 SD length/weight for age), wasting ( $->2 \mathrm{SD}$ weight for length/height), and underweight (->2 SD weight for age) [43]. In developing countries, an estimated $32 \%$ of children under five were stunted, $3.5 \%$ were severely wasted, and $20.2 \%$ were underweight [4]. The rate of stunting in India has declined from $48 \%$ to $38.4 \%$, wasting has increased slightly from $19.8 \%$ to $21 \%$, and underweight has decreased from $42.5 \%$ to $35.8 \%$ between the two time-periods of NFHS3 and NFHS-4 [17]. Malnutrition in India is clustered in central, northern, and eastern regions [46]. In a study conducted in Indian settings, it was found that the spatial clustering of malnutrition was visible in those geographical pockets where poverty was high, women's education was low, and BMI level among women was below average [22].

Malnutrition is primarily caused due to the immediate causes (inadequate dietary intake, lack of care and onset of disease), and the underlying causes (an unhealthy environment and insufficient education) [9]. Studies in countries other than India had also raised the issue of child growth significantly. In a study, it was found that there was a substantial poor/rich gap in the nutritional status in the urban residence of Kenya [11]. Moreover, the same study argued that poor nutritional status in urban areas is attributed to poor environment and housing, poor access to drinking water, food, and health services. One of the studies found that the children belonging to poor households were undernourished not only because of poverty, but also due to limited use of maternal health care services and poor care resulting from the lower educational status of parents and poor health of mothers [5].

Despite high levels of stunting, wasting, and underweight among under-five children in India, studies related to measuring growth faltering as measured with $\mathrm{z}$ score are very limited [14]. Studies have found that growth in weight appeared to start right from birth, and there appeared a fall in WAZ score for the first 3 months, and after that, the rate of fall appeared to slow down [25]. The study was done to compare NFHS-1 and NFHS-3 data to provide a comparison for all India level growth among children aged 0-3 years [25]. Growth in infancy was associated with poorer educational outcomes in later childhood. However, these outcomes, when adjusted for confounding factors, suggested that childhood educational attainment was more strongly influenced by other socio-demographic factors, especially maternal education and the quality of the home environment $[15,42]$. Similarly, it was found that early childhood stunting is associated with deficits in cognition and educational achievement in late adolescence [42].

India ranks 102 in the Global Hunger Index [12], shows the severity of under-nutrition existence in the country. Moreover, other studies too carved out the fact that the poverty nutrition trap does exist in India [19]. There exist lack of literature focusing on examining the socio-economic gap for malnutrition among children in urban India. Therefore, this paper aims to measure undernutrition among urban poor and non-poor children below age five in India. It also analyses the changes in socio-economic inequality in undernutrition among children in urban India from 2005 to 06 to 2015-16.

\section{Methods}

\section{Data}

The data used in this paper have been taken from two rounds of National Family Health Survey namely NFHS3 (2005-06) and NFHS-4 (2015-16). The primary objective of the NFHS was to provide essential data on health and family welfare, as well as data on emerging issues including the nutritional status of children under age five at national, state, and district levels. Therefore, data from NFHS-4 (2015-16) was considered as a benchmark to examine the progress made by the country in various health indicators over time. Decisions about the overall sample size required for National Family Health Survey (2005-06 and 2015-16) were guided by several considerations, paramount among which was the need to produce indicators at the national levels, as well as separate estimates for urban and rural areas. The data is a nationally representative data which provide essential data on health and family welfare, as well as data on emerging issues in these areas. Additionally, National Family Health Survey is a part of Demographic and Health Surveys (DHS) which are nationally-representative household surveys that provide data for a wide range of monitoring and impact evaluation indicators in the areas of population, health, and nutrition. The findings of this study are based on a total of 15,241 urban children under 5 years in NFHS-3 and 53,483 urban children under five years in NFHS-4. The information related to child's anthropometric measures covered measurements of height, 
weight and hemoglobin levels for children; Details about the NFHS-4 designs, tools, and protocols are presented in the national report of NFHS-4 [17], and all relevant information is available in the public domain on http://rchiips. org/ NFHS.

\section{Categorization of variables Outcome variable}

The three anthropometric indicators were used for children under five years: stunting (height for age $<-2$ standard deviation (SD)), underweight (weight for age < $-2 \mathrm{SD}$ ), and wasting (height for age $<-2 \mathrm{SD}$ ). The measure used was recoded as per WHO standards [45].

\section{Predictor variable}

The study divided the predictors into five groups. 1) Maternal Factors 2) Socio-economic factors 3) Child-related factors 4) Environmental factors and 5) Health seeking factors. Maternal factors include age (15-24, 25-24 and $35+$ years), Education (Illiterate and literate), age at first birth $(<18,18-30$, and $>30$ years), Parity $(1,2,3,4+)$ and mother's anaemia status (no and yes). Socioeconomic factors include caste (SC/ST and non-SC/ST), religion (Hindu, Muslim, Christian, and Others) and Wealth status (Poorest, Poorer, Middle, Richer, and Richest). Child factors consist age (0-23, 24-47 months and 47-59 months), sex of the child (male and female), anemia status (no and yes), diarrhea, birth weight (normal and low birth weight $(<2500 \mathrm{grms})$, and colostrum feeding (yes and no). The environmental factors include the source of drinking water (protected and not protected), open defecation (opened and improved), stool disposal (yes and no), and geographical regions (North, Central, East, North-east, West, and South). Health seeking factors included the use of Skill Birth Attendants, Place of delivery (Home or any institution i.e., private/ public hospital), full immunization includes children who received BCG (for tuberculosis), measles, and three doses each of DPT (diphtheria, whooping cough, and tetanus), and Polio. Full ANC is defined as women who had four or more ANC visits, had at least two tetanus injection, and consumed 100 IFA tablets/syrup for the most recent birth. Further, Colostrum feeding, defined as a child received breastfeeding within $1 \mathrm{~h}$ after delivery.

The variable of wealth status was created using the information given in the survey. Households were given scores based on the number and kinds of consumer goods they own, ranging from a television to a bicycle or car, and housing characteristics such as source of drinking water, toilet facilities, and flooring materials. These scores are derived using principal component analysis. National wealth quintiles are compiled by assigning the household score to each usual (de jure) household member, ranking each person in the household population by their score, and then dividing the distribution into five equal categories, each with $20 \%$ of the population. Further, wealth status of the household was recoded as poor and non-poor. To depict the poor and non-poor differentials, we clubbed first two wealth quintiles as poor (poorest and poorer) and next three quintiles as non-poor (middle, richer and richest).

\section{Statistical analysis \\ Concentration index $(\mathrm{Cl})$}

The concentration curve is obtained by plotting the cumulative proportion of outcome variables (either stunting, underweight, or wasting) on $y$-axis against the increasing percentage of the population ranked by the socio-economic indicator (wealth index) on $\mathrm{x}$-axis. The curves shows that whether the socio- economic status related inequality in the outcome variable (on $\mathrm{x}$-axis) prevails or not. If the curve is above the line of equality (45 degree line) that means the index value is negative hence it shows that the outcome variable is disproportionally concentrated among the poor and vice-versa. Income-related inequality in stunting, underweight, and wasting was measured by the concentration index (CI) and the concentration curve (CC), using the wealth score as the socio-economic indicator and binary outcome as stunting, underweight, and wasting. The concentration index is defined as twice the area between the concentration curve and the line of equality. Concentration index measures the inequality of one variable (say stunting, underweight or wasting) over the distribution of another variable (wealth index). The index ranges from -1 to +1 , where the index value of 0 (zero) shows no socio-economic inequality. However, positive value of index shows pro-rich inequality and vice-versa. Additional on the either scales higher the value, higher the extent of socio-economic inequality. The study used Wagstaff decomposition analysis to decompose the concentration index. Wagstaff's decomposition demonstrated that the concentration index could be decomposed into the contributions of each factor to the income-related inequalities [41]. For any linear regression model on health outcome (y) (say stunting, underweight or wasting), such as.

$$
y=\alpha+\sum_{k} \beta_{k} x_{k}+\varepsilon
$$

The concentration index for $\mathrm{y}, \mathrm{C}$, can be written as follows,

$$
C=\sum_{k}\left(\beta_{k} \bar{x}_{k} / \mu\right) C_{k}+G C_{\varepsilon} / \mu
$$

Where $\mu$ is the mean of $\mathrm{y}, \bar{x}_{k}$ is the mean of $x_{k}, C_{k}$ is the concentration index for $x_{k}$ (defined analogously to 
C), and $G C_{\varepsilon}$ is the generalized concentration index for the error term $(\varepsilon)$. Equation (2) shows that $C$ is equal to a weighted sum of the concentration indices of the $\mathrm{k}$ regressors, where the weight for $x_{k}$ is the elasticity of $y$ with respect to $x_{k}\left(\eta_{k}=\beta_{k} \frac{\bar{x}_{k}}{\mu}\right)$. The residual component captured by the last term reflects the socio-economic status related inequality in health that is not explained by systematic variation in the regressors by income, which should approach zero for a well-specified model. Each contribution is the product of elasticity with the degree of economic inequality. Moreover, the percentage contribution is obtained by dividing each absolute contribution by total absolute contribution multiplied by 100 to obtain the estimates.

\section{Results}

Table 1 shows the distribution of children under age five by selected background characteristics among urban poor and non-poor in India. It was found that significant health problems like anaemia and diarrhoea among under-five children were more prevalent among those from urban poor as compared to those from urban nonpoor. On contrary, health-seeking behaviour was better practised by urban residents as compared to non-poor population.

Figure 1 portrays the prevalence of child growth as measured through stunting, wasting, and underweight among urban poor and non-poor in India, during 200506 and 2015-16. It is evident from the results that three key indicators of growth among children under age five, namely stunting, underweight, and wasting were higher among urban poor children than among urban non-poor children for both the time-periods. Further, results show that the prevalence of stunting and underweight has declined among urban poor as well as non-poor children during the last one decade, i.e., from 2005 to 06 to 2015-16. However, the prevalence of wasting has increased, from 2005 to 06 to 2015-16, among urban poor as well as urban non-poor children, which may be primarily due to seasonal variation in the month of surveys. By and large, a similar result has been found in case of growth for poor and non-poor children in urban India during 2005-06 and 2015-16. The result found that the average growth is higher among urban poor than in urban non-poor for each classification of child anthropometry measures (Figure-S1; Supplementary file). For standard error, please refer supplementary Table S1 and S2.

Table 2 presents the average growth among children as measured through z scores for HAZ, WHZ, and WAZ by segregating them into different age groups. Mean WAZ, HAZ and WHZ scores for children under 5 months were $(-0.95,-1.54,-1.11)$, and $(-0.36,-1.05,-1.00)$ in $2005-$ 06 ; and $(-0.86,-1.49,-1.09)$, and $(-0.33,-1.18,-1.25)$ in 2015-16 for urban poor and non-poor respectively. Significant differences in $\mathrm{z}$ score in poor as well as non-poor children were visible from the first 5 months itself. Of the total growth differential as measured with $\mathrm{z}$ score for height-for-age (HAZ) at 59 months among urban poor and non-poor in 2005-06 (- 2.51 and - 1.59), 38\% (- 0.95) and $22 \%(-0.36)$ of growth took place at first 5 months after birth; whereas, in 2015-16, the distribution increased to $41 \%(-0.86)$ and $25 \%(-0.33)$ respectively. Similarly, of the average growth in weight-for-age (WAZ) at 59 months among urban poor and non-poor in 2005-06 $(-2.18$ and $-1.54), 71 \%(-1.54)$ and $68 \%(-1.05)$ of growth took place at first 5 months after birth; whereas, in 2015-16, the distribution was $41 \%(-0.86)$ and $25 \%(-0.33)$ respectively. For weight-for-height (WHZ) at 59 months among urban poor and non-poor in 2005-06 (- 0.99 and $-0.88), 112 \%(-1.11)$ and $113 \%(-1.00)$ of growth took place at first 5 months after birth; whereas in 2015-16, the distribution was $99 \%(-1.09)$ and $131 \%(-1.25)$ respectively. Growth for HAZ among children was found to be highest at age 21-25 months among urban poor, and at age 46-50 months among urban non-poor during 200506 , whereas, growth in stunting was highest at age 21-25 months among urban poor and non-poor during 201516. It leads to the premise that the children were more susceptible to be stunted during the age of 21-25 months. $\mathrm{Z}$ score for WAZ among children was found to be highest at age 31-35 months among urban poor and at age 5659 months among urban non-poor during 2005-06, whereas, z score for underweight was highest at age 2125 months among urban poor and at age 56-59 months among urban non-poor during 2015-16. It means that urban non-poor children aged 56-59 months were more prone to be underweight. The $\mathrm{z}$ scores for WHZ among children was found to be highest at age 6-10 months among urban poor and at age $0-5$ months among urban non-poor during 2005-06, whereas, z score for wasting was highest at age 6-10 months among urban poor and at age 0-5 months among urban non-poor during 2015-16. It means that children in their early months were more prone to be wasted.

Figure 2 depict concentration curves for stunting, wasting, and underweight among children in urban India, during 2005-06 and 2015-16. The result of the concentration curve shows a reduction in the inequality for all three indicators among children below five years in urban India. However, there was a significant decrement in the inequality for stunting, underweight and wasting; the decrement was much faster in wasting (CI: 0.116 [Se: 0.010; $p<0.05$ ] in 2005-06 to 0.045 [Se: 0.003; $p<0.05$ ] in 2015-16) than in stunting (CI: 0.213 [Se: 0.006; $p<0.05$ ] in 2005-06 to 0.162 [Se; $0.004 ; p<0.05$ ] in 2015-16) or underweight (CI: 0.186 [Se: $0.005 ; p<0.05$ ] in 2005-06 to 0.156 [Se; 0.004; $p<0.05$ ] in 2015-16). 
Table 1 Percentage distribution of children under age five years by selected background characteristics among urban poor and non-poor in India, 2005-06 and 2015-16.

\begin{tabular}{|c|c|c|c|c|c|c|c|c|}
\hline \multirow[t]{3}{*}{ Variables } & \multicolumn{4}{|c|}{ 2005-06 } & \multicolumn{4}{|c|}{ 2015-16 } \\
\hline & \multicolumn{2}{|c|}{ Non-poor } & \multicolumn{2}{|l|}{ Poor } & \multicolumn{2}{|c|}{ Non-poor } & \multicolumn{2}{|l|}{ Poor } \\
\hline & $\bar{N}$ & $\%$ & $\overline{\mathrm{N}}$ & $\%$ & $\bar{N}$ & $\%$ & $\bar{N}$ & $\%$ \\
\hline \multicolumn{9}{|l|}{ Age (years) } \\
\hline $15-24$ & 4502 & 32.9 & 607 & 39.2 & 12,235 & 27.0 & 2843 & 34.6 \\
\hline $25-34$ & 8099 & 59.2 & 756 & 48.8 & 28,657 & 63.3 & 4443 & 54.1 \\
\hline $35+$ & 1092 & 8.0 & 185 & 12.0 & 4374 & 9.7 & 931 & 11.3 \\
\hline \multicolumn{9}{|l|}{ Education } \\
\hline No & 2711 & 19.8 & 1023 & 66.1 & 5357 & 11.8 & 3747 & 45.6 \\
\hline Yes & 10,982 & 80.2 & 525 & 33.9 & 39,909 & 88.2 & 4470 & 54.4 \\
\hline \multicolumn{9}{|c|}{ Age at First Birth (years) } \\
\hline Less than 18 & 2210 & 16.1 & 626 & 40.44 & 3503 & 7.7 & 1561 & 19.0 \\
\hline $18-30$ & 11,002 & 80.4 & 910 & 58.8 & 40,202 & 88.8 & 6520 & 79.4 \\
\hline More than 30 & 481 & 3.5 & 12 & 0.78 & 1561 & 3.5 & 136 & 1.7 \\
\hline \multicolumn{9}{|l|}{ Parity } \\
\hline 1 & 3577 & 26.1 & 223 & 14.4 & 14,131 & 31.2 & 1506 & 18.3 \\
\hline 2 & 5334 & 39.0 & 344 & 22.2 & 18,883 & 41.7 & 2515 & 30.6 \\
\hline 3 & 2423 & 17.7 & 300 & 19.4 & 7620 & 16.8 & 1901 & 23.1 \\
\hline $4+$ & 2359 & 17.2 & 681 & 44.0 & 4632 & 10.2 & 2295 & 27.9 \\
\hline \multicolumn{9}{|l|}{ Anemia } \\
\hline No & 7045 & 51.5 & 592 & 38.2 & 22,264 & 49.2 & 3312 & 40.3 \\
\hline Yes & 6648 & 48.6 & 956 & 61.8 & 23,002 & 50.8 & 4905 & 59.7 \\
\hline \multicolumn{9}{|c|}{ Socio-economic factors } \\
\hline \multicolumn{9}{|l|}{ Caste } \\
\hline SC/ST & 3406 & 24.9 & 565 & 36.5 & 12,103 & 26.7 & 3269 & 39.8 \\
\hline Non-SC/ST & 10,287 & 75.1 & 983 & 63.5 & 33,163 & 73.3 & 4948 & 60.2 \\
\hline \multicolumn{9}{|l|}{ Religion } \\
\hline Hindu & 9143 & 66.8 & 1013 & 65.4 & 29,762 & 65.8 & 5508 & 67.0 \\
\hline Muslim & 2714 & 19.8 & 413 & 26.7 & 10,077 & 22.3 & 2024 & 24.6 \\
\hline Others & 1836 & 13.4 & 122 & 7.9 & 5427 & 12.0 & 685 & 8.3 \\
\hline
\end{tabular}

\section{Child factors}

Age (months)

Vor

$$
24-47
$$$$
\text { 47-59 }
$$

Sex

$$
\text { Male }
$$

\section{Anemia}

No
Yes

Diarrhea

No
Yes

5115

5741

2837

7223

6470

7208

6485

12,409

1284

$\begin{array}{ll}37.4 & 576 \\ 41.9 & 639 \\ 20.7 & 333\end{array}$

20.7

52.8

47.3

52.6

47.4

90.6

9.4
37.2

41.3

21.5

48.3

51.7

39.0

61.0

944

1396

152
90.2

9.8
17,199

18,777

9290

23,666

21,600

23,501

21,765

41,256

4010
38.0

41.5

3071

3399

1747

52.3

4221

3996

3719

4498

45.3

48.1

91.1

7411

90.2

8.9

806 
Table 1 Percentage distribution of children under age five years by selected background characteristics among urban poor and non-poor in India, 2005-06 and 2015-16. (Continued)

\begin{tabular}{|c|c|c|c|c|c|c|c|c|}
\hline \multirow[t]{3}{*}{ Variables } & \multicolumn{4}{|c|}{ 2005-06 } & \multicolumn{4}{|c|}{ 2015-16 } \\
\hline & \multicolumn{2}{|c|}{ Non-poor } & \multicolumn{2}{|l|}{ Poor } & \multicolumn{2}{|c|}{ Non-poor } & \multicolumn{2}{|l|}{ Poor } \\
\hline & $\mathbf{N}$ & $\%$ & $\mathbf{N}$ & $\%$ & $\mathbf{N}$ & $\%$ & $\mathbf{N}$ & $\%$ \\
\hline \multicolumn{9}{|c|}{ Birth weight } \\
\hline Normal & 12,003 & 87.7 & 1462 & 94.4 & 38,744 & 85.6 & 7086 & 86 \\
\hline LBW & 1690 & 12.3 & 86 & 5.6 & 6522 & 14.4 & 1131 & 1 \\
\hline \multicolumn{9}{|c|}{ Colostrum feeding $^{a}$} \\
\hline No & 8925 & 65.2 & 1136 & 73.4 & 30,234 & 66.8 & 5634 & 68 \\
\hline Yes & 4768 & 34.8 & 412 & 26.6 & 15,032 & 33.2 & 2583 & 31 \\
\hline
\end{tabular}

Environmental factors

Source of drinking water

$\begin{array}{lllllllll}\text { Not Protected } & 1097 & 8.0 & 211 & 13.6 & 3889 & 8.6 & 965 & 11.7 \\ \text { Protected } & 11,840 & 86.5 & 1259 & 81.3 & 39,039 & 86.2 & 6842 & 83.3 \\ \text { Others } & 756 & 5.5 & 78 & 5.0 & 2338 & 5.2 & 410 & 5.0\end{array}$

Defecation

Improved

$\begin{array}{lll}1089 & 8.0 & 940\end{array}$

60.7

2725

6.0

4309

52.4

Others

11,790

86.1

511

40,065

88.5

3456

42.1

Stool Disposal

$$
\text { Yes }
$$

No

11,382
2308

83.1

824

16.9

724

6.3

2476

5.5

36,300

8955

53.2
46.8

Regions of India

North

Central

3029

22.1

315

East

North East

West

South

Health seeking factors

Skilled birth attendant ${ }^{\mathrm{a}}$

No

Yes

Place of delivery ${ }^{\mathrm{a}}$

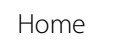

Institution

Full Immunization

No
Yes

166

14.8

2032

3023

2823

2223

4.1

22.1

20.6

16.2

2987

21.8

986

78.2

562

63.7

36.3

1084

27.4

72.6

464

41.2

5643

8050

58.8

1088

460

70.3

29.7

82.6

17.4

1494

54

2378

96.5

10,054

12,640

4634

5675

4745

7518

80.2

452

5.5

Full ANC ${ }^{\mathrm{a}}$

Yes

SC/ST Scheduled Caste/Scheduled Tribe; ANC Ante-Natal Care

a estimates only for last birth; N: Sample; \% Percentage 


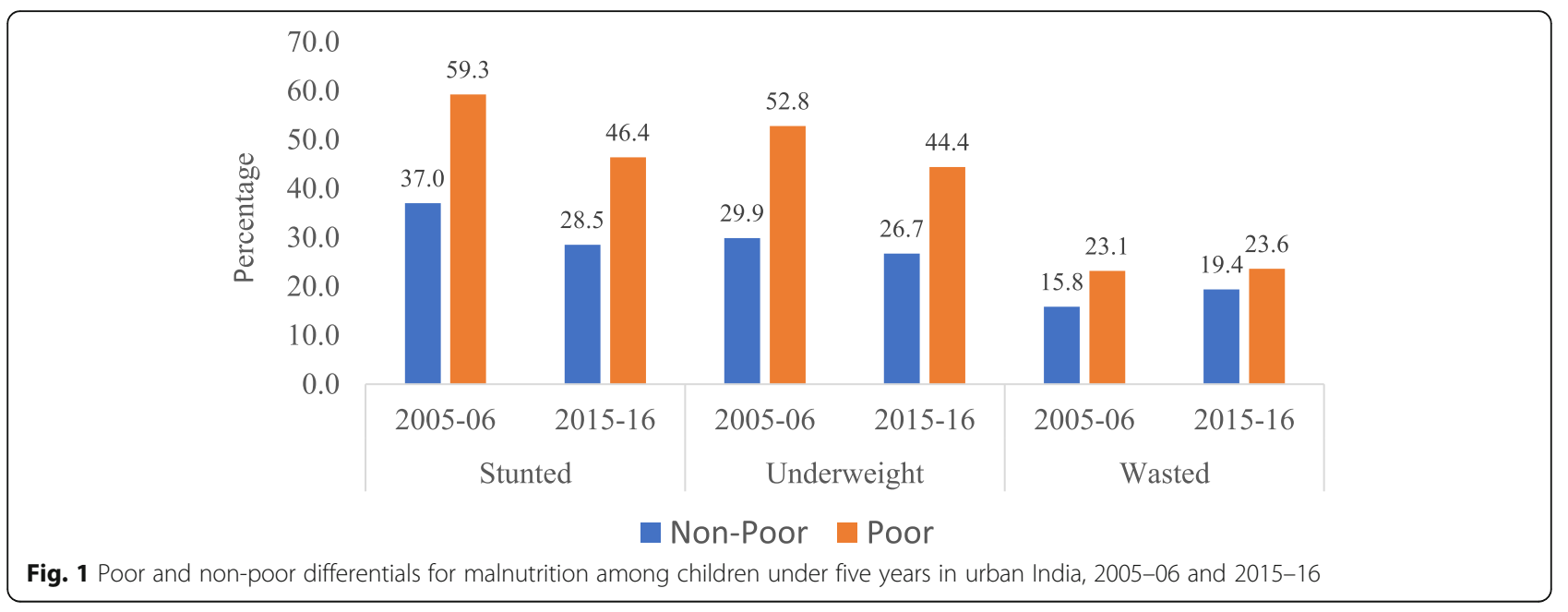

Table 3 presents the estimates of decomposition analysis for the contribution of various explanatory variables for stunting among urban children in India in 2005-06 \& 2015-16. The absolute CI for stunting decreased from -0.186 in 2005-06 to -0.156 in 2015-16, which depicts that economic inequality has significantly decreased over the two time-periods $(0.03 ; p<0.05)$. In 2005-06, education of the mother explained about $19 \%$ of the observed inequality in the prevalence of stunting among children, which increased to around 27\% during 2015-16. Most of the economic inequality in stunting during 2015-16 was explained through mother's education, parity, defecation, and stool disposal. During 2015-16, education explained $26.6 \%$ of the observed inequality in stunting among children, followed by $19 \%$ by parity and $14.3 \%$ by defecation. During both periods, more than $85 \%$ of the economic inequality for stunting among children had been explained by three factors, namely; maternal factors, health-seeking factors, and environmental factors. Maternal factors remained the most significant contributor to inequality during both the time-periods. The contribution of environmental factors in explaining the disparity had increased by about $10 \%$ from $13.3 \%$ in $2005-06$ to $23.2 \%$ in 2015-16. However, the contribution of health-seeking factors in explaining the inequality had declined from $30.6 \%$ in $2005-06$ to $10.4 \%$ in $2015-16$.

Table 4 presents the estimates of decomposition analysis for the contribution of various explanatory variables for underweight among urban children in India, during 2005-06 \& 2015-16. The actual CI for underweight decreased from -0.213 in $2005-06$ to -0.162 in $2015-16$, which depicts a significant reduction in economic inequality $(0.051, p<0.05)$. In explaining economic inequality for underweight in 2005-06, maternal education (28.8\%) was the most significant contributor in explaining the majority of the inequality followed by open defecation (16.9\%), and place of delivery (16.7\%). In 2015-16, the contribution of maternal education slightly decreased to $25.4 \%$, but remained as a significant contributor in explaining the inequality followed by open defecation (17.5\%), and parity (16.3\%). In 2015-16, nearly half of the economic disparities in underweight among urban children was explained by maternal factors (49\%), followed by environmental factors $(25.4 \%)$, and health seeking factors (14.4\%).

Table 5 presents the estimates of decomposition analysis for the contribution of various explanatory variables for wasting among urban children in India, 2005-06 \& 2015-16. The actual CI for wasting decreased from 0.116 in $2005-06$ to -0.045 in $2015-16$, which depicts that economic inequality has significantly decreased over time $(0.071, \mathrm{p}<0.05)$. Unlike for stunting and underweight, defecation (36.8\%) explained the majority of the economic inequality in wasting during 2005-06, which further increased to $(46.9 \%)$ in $2015-16$. The contribution of maternal education in the explanation of economic inequality decreased from (33.4\%) in 2005-06 to (11.8\%) in 2015-16. In 2015-16, environmental factors (55.9\%) explained most of the gap for economic inequality for wasted children in India, followed by maternal factors $(22.2 \%)$ and Health seeking factors (22.2\%).

\section{Discussion}

Despite recent achievements in economic progress, India failed to ensure better outcomes in child growth. Results further suggested that there exists socio-economic clustering that is further widening the gap in securing development among children. Through this study, we have tried to explain the factors contributing to economic inequality in stunting, underweight, and wasting among children below five years in urban India.

There is little data to understand the timing of growth faltering in under-five age children in India, and whatever limited study conducted to understand the growth faltering among children measured growth faltering 
Table 2 Mean height for age z (HAZ), weight for age z (WAZ), and weight for height z (WHZ) scores among children under five years in urban India, 2005-06 and 2015-16

\begin{tabular}{|c|c|c|c|c|c|c|c|c|c|c|c|c|}
\hline \multirow{3}{*}{$\begin{array}{l}\text { Age (in } \\
\text { Months) }\end{array}$} & \multicolumn{6}{|c|}{$2005-06$} & \multicolumn{6}{|c|}{ 2015-16 } \\
\hline & \multicolumn{3}{|c|}{ Urban Poor } & \multicolumn{3}{|c|}{ Urban Non-poor } & \multicolumn{3}{|c|}{ Urban Poor } & \multicolumn{3}{|c|}{ Urban Non-poor } \\
\hline & $n$ & Mean & SD & $\mathrm{n}$ & Mean & SD & $n$ & Mean & SD & $n$ & Mean & SD \\
\hline \multicolumn{13}{|c|}{$0-5$ months } \\
\hline HAZ & 100 & -0.95 & 1.78 & 773 & -0.36 & 1.90 & 521 & -0.86 & 1.91 & 2808 & -0.33 & 1.88 \\
\hline VWAZ & 100 & -1.54 & 1.63 & 773 & -1.05 & 1.30 & 521 & -1.49 & 1.32 & 2808 & -1.18 & 1.31 \\
\hline WHZ & 100 & -1.11 & 1.75 & 773 & -1.00 & 1.91 & 521 & -1.09 & 1.79 & 2808 & -1.25 & 1.84 \\
\hline \multicolumn{13}{|c|}{ 5-10 months } \\
\hline $\mathrm{HAZ}$ & 127 & -1.41 & 1.97 & 1153 & -0.61 & 1.68 & 712 & -0.73 & 2.07 & 3784 & -0.33 & 1.85 \\
\hline WAZ & 127 & -2.06 & 1.43 & 1153 & -1.08 & 1.28 & 712 & -1.56 & 1.38 & 3784 & -1.06 & 1.27 \\
\hline WHZ & 127 & -1.44 & 1.62 & 1153 & -0.85 & 1.57 & 712 & -1.34 & 1.57 & 3784 & -1.02 & 1.63 \\
\hline \multicolumn{13}{|c|}{$10-15$ months } \\
\hline $\mathrm{HAZ}$ & 112 & -1.82 & 1.53 & 1105 & -1.14 & 1.58 & 612 & -1.51 & 1.89 & 3600 & -0.88 & 1.90 \\
\hline WAZ & 112 & -1.91 & 1.26 & 1105 & -1.19 & 1.21 & 612 & -1.71 & 1.30 & 3600 & -1.10 & 1.26 \\
\hline WHZ & 112 & -1.32 & 1.43 & 1105 & -0.82 & 1.43 & 612 & -1.22 & 1.49 & 3600 & -0.84 & 1.52 \\
\hline \multicolumn{13}{|c|}{ 15-20 months } \\
\hline $\mathrm{HAZ}$ & 157 & -2.24 & 1.76 & 1172 & -1.62 & 1.60 & 702 & -1.74 & 1.83 & 3977 & -1.27 & 1.72 \\
\hline WAZ & 157 & -2.04 & 1.30 & 1172 & -1.27 & 1.24 & 702 & -1.75 & 1.22 & 3977 & -1.18 & 1.22 \\
\hline WHZ & 157 & -1.30 & 1.47 & 1172 & -0.68 & 1.32 & 702 & -1.24 & 1.30 & 3977 & -0.78 & 1.41 \\
\hline \multicolumn{13}{|c|}{$20-25$ months } \\
\hline HAZ & 100 & -2.76 & 1.52 & 1133 & -1.76 & 1.56 & 656 & -2.15 & 1.63 & 3771 & -1.42 & 1.73 \\
\hline WAZ & 100 & -2.19 & 1.39 & 1133 & -1.47 & 1.17 & 656 & -2.01 & 1.16 & 3771 & -1.28 & 1.29 \\
\hline WHZ & 100 & -1.10 & 1.49 & 1133 & -0.81 & 1.22 & 656 & -1.27 & 1.23 & 3771 & -0.79 & 1.41 \\
\hline \multicolumn{13}{|c|}{$25-30$ months } \\
\hline HAZ & 138 & -2.33 & 1.61 & 1227 & -1.61 & 1.54 & 667 & -1.94 & 1.68 & 3819 & -1.07 & 1.74 \\
\hline WAZ & 138 & -2.05 & 1.10 & 1227 & -1.38 & 1.18 & 667 & -1.88 & 1.17 & 3819 & -1.23 & 1.21 \\
\hline WHZ & 138 & -1.10 & 1.10 & 1227 & -0.73 & 1.21 & 667 & -1.17 & 1.29 & 3819 & -0.94 & 1.28 \\
\hline \multicolumn{13}{|c|}{ 30-35 months } \\
\hline HAZ & 134 & -2.61 & 1.81 & 1196 & -1.72 & 1.61 & 697 & -1.92 & 1.48 & 3877 & -1.38 & 1.52 \\
\hline WAZ & 134 & -2.25 & 1.22 & 1196 & -1.49 & 1.23 & 697 & -1.82 & 1.14 & 3877 & -1.34 & 1.19 \\
\hline WHZ & 134 & -1.10 & 1.20 & 1196 & -0.77 & 1.29 & 697 & -1.07 & 1.21 & 3877 & -0.85 & 1.29 \\
\hline \multicolumn{13}{|c|}{$35-40$ months } \\
\hline HAZ & 133 & -2.52 & 1.61 & 1227 & -1.66 & 1.64 & 710 & -1.97 & 1.49 & 3900 & -1.28 & 1.53 \\
\hline WAZ & 133 & -2.13 & 1.00 & 1227 & -1.53 & 1.27 & 710 & -1.91 & 1.08 & 3900 & -1.37 & 1.20 \\
\hline WHZ & 133 & -0.98 & 1.02 & 1227 & -0.86 & 1.24 & 739 & -1.14 & 1.33 & 3900 & -0.95 & 1.34 \\
\hline \multicolumn{13}{|c|}{$40-45$ months } \\
\hline $\mathrm{HAZ}$ & 134 & -2.46 & 1.56 & 1219 & -1.70 & 1.50 & 739 & -1.91 & 1.54 & 4041 & -1.23 & 1.46 \\
\hline WAZ & 134 & -2.01 & 1.35 & 1219 & -1.50 & 1.11 & 739 & -1.89 & 1.16 & 4041 & -1.28 & 1.21 \\
\hline WHZ & 134 & -0.83 & 1.47 & 1219 & -0.75 & 1.18 & 710 & -1.13 & 1.28 & 4041 & -0.85 & 1.32 \\
\hline \multicolumn{13}{|c|}{$45-50$ months } \\
\hline $\mathrm{HAZ}$ & 131 & -2.48 & 1.68 & 1098 & -1.85 & 1.63 & 749 & -1.93 & 1.42 & 3976 & -1.31 & 1.45 \\
\hline WAZ & 131 & -2.10 & 1.47 & 1098 & -1.69 & 1.20 & 749 & -1.98 & 1.06 & 3976 & -1.39 & 1.14 \\
\hline WHZ & 131 & -0.90 & 1.50 & 1098 & -0.87 & 1.25 & 749 & -1.24 & 1.19 & 3976 & -0.92 & 1.33 \\
\hline
\end{tabular}


Table 2 Mean height for age $\mathrm{z}(\mathrm{HAZ})$, weight for age $\mathrm{z}$ (WAZ), and weight for height $\mathrm{z}$ (WHZ) scores among children under five years in urban India, 2005-06 and 2015-16 (Continued)

\begin{tabular}{|c|c|c|c|c|c|c|c|c|c|c|c|c|}
\hline \multirow{3}{*}{$\begin{array}{l}\text { Age (in } \\
\text { Months) }\end{array}$} & \multicolumn{6}{|c|}{$2005-06$} & \multicolumn{6}{|c|}{ 2015-16 } \\
\hline & \multicolumn{3}{|c|}{ Urban Poor } & \multicolumn{3}{|c|}{ Urban Non-poor } & \multicolumn{3}{|c|}{ Urban Poor } & \multicolumn{3}{|c|}{ Urban Non-poor } \\
\hline & $n$ & Mean & SD & $n$ & Mean & SD & $n$ & Mean & SD & $n$ & Mean & SD \\
\hline \multicolumn{13}{|c|}{$50-55$ months } \\
\hline $\mathrm{HAZ}$ & 145 & -2.62 & 1.20 & 1238 & -1.46 & 1.39 & 718 & -1.91 & 1.34 & 3883 & -1.28 & 1.35 \\
\hline WAZ & 145 & -2.22 & 1.06 & 1238 & -1.39 & 1.17 & 718 & -1.83 & 1.09 & 3883 & -1.35 & 1.21 \\
\hline WHZ & 145 & -0.95 & 1.26 & 1238 & -0.78 & 1.27 & 718 & -1.03 & 1.18 & 3883 & -0.89 & 1.39 \\
\hline \multicolumn{13}{|c|}{$55-60$ months } \\
\hline $\mathrm{HAZ}$ & 137 & -2.51 & 1.29 & 1152 & -1.59 & 1.36 & 734 & -2.08 & 1.20 & 3830 & -1.34 & 1.26 \\
\hline WAZ & 137 & -2.18 & 1.02 & 1152 & -1.54 & 1.16 & 734 & -1.98 & 0.95 & 3830 & -1.43 & 1.14 \\
\hline WHZ & 137 & -0.99 & 1.21 & 1152 & -0.88 & 1.19 & 734 & -1.09 & 1.15 & 3830 & -0.96 & 1.37 \\
\hline
\end{tabular}

through reference growth standards of NCHS (National Centre for Health Statistics) methodology [25]. This study has the edge over previous studies in measuring growth faltering as this study used WHO standards to measure the growth faltering among children over NCHS methodology [34]. The result confirms that wasting among urban poor and non-poor children was more prone during the first year of birth, and stunting among urban poor and non-poor children is more prone during the second year of birth. Growth flattering in underweight is more during the second year of birth among urban poor children and the fifth year of birth among urban non-poor children. Critically, children aged 2125 months were more prone to growth faltering than the children of any other age group. Studies found that children in low-middle-income countries experience rapid growth faltering during the first two years of life [40].

Maternal factors remained a prime contributor to inequality. Stunting in simple terms is defined as $->2 \mathrm{SD}$ height-for-age [38], and measures the past or chronic child undernutrition. The mother's related factors explained a little more than half of the inequality for stunting among children during 2015-16. Various studies in Indian set up are in coordination with this study, concluded that maternal factors such as mother's age mother's education, age at first birth, parity, and anaemia were highly associated with stunting $[28,36]$. Of all the mother's factors, mother's education is the most significant contributor to the economic inequality in defining stunting among children. Not only in India [10], but in developed [44] and developing countries [2, 20] also, mother's education was found significantly associated with stunting among children. Among environmental factors, defecation and stool disposal explained the highest economic inequality in stunting among children. A study conducted in Rwanda for 10 years, using decomposition analysis reported that defecation has no association with stunting [30]. Another study conducted in rural Zimbabwe employing cluster-randomized trials found that WASH (Water, Sanitation, and Hygiene) practices implemented in rural areas are unlikely to reduce stunting [16]. However, few studies found that sanitation and defecation significantly affect stunting among children [24]. A study conducted in Indian settings utilizing NFHS data concluded that the practice of open defecation influences the inequality in stunting [35]. Health seeking factors explained about $30 \%$ of the inequality in stunting in 2005-06, and in 2015-16, it could only explain about $10 \%$ of the inequality. From various works of literature, it can be summed up that full Antenatal Care and Skill attendants at birth had increased over time in India [1].

Underweight is defined as - > 2 SD weight-for-age, and it depicts the past as well as present undernutrition. During both the time, mother's factors remained the highest contributory factors that explained the inequality in underweight among children aged 0-5 years. Employing the decomposition approach, a study concluded that maternal factors improve WAZ among children aged 0 5 years in India [27]. In other studies also, the role of mother's education in explaining the inequalities in underweight was highlighted in Indian settings [29, 35]. Of the environmental factors, defecation remained the highest contributor to the inequality in underweight with nearly $17 \%$, during both the time-periods. Open defecation is a problem among masses in India, and recently the Indian Government has done well to tackle the issue [6]. On the base of the decomposition approach, a study conducted in India confirmed that open defecation positively influences the inequality in underweight [35]. A study conducted in five Indian states; Uttar Pradesh, Karnataka, Madhya Pradesh, Rajasthan, and West Bengal, found that children from open defecation free (ODF) districts were less underweight than children in non-ODF districts [37], thus confirming the importance of open defecation in understanding the 


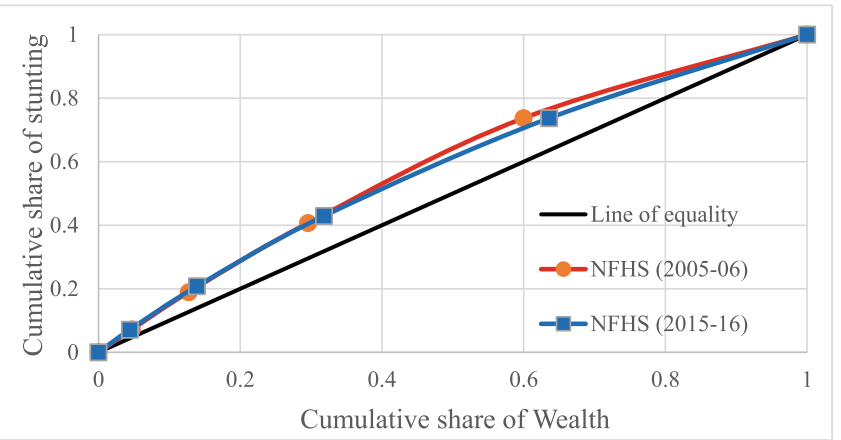

Concentration curve for stunting among children under five years in Urban India (2005-06 \& 2015-16)

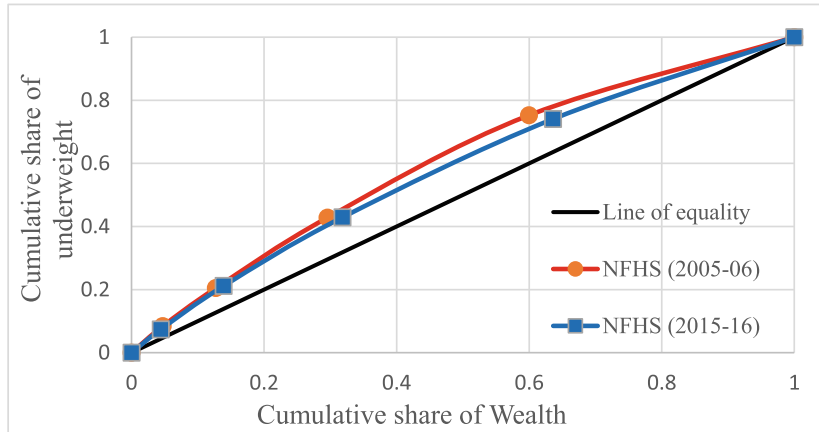

Concentration curve for underweight among children under five years in Urban India (2005-06 \& 2015-16)

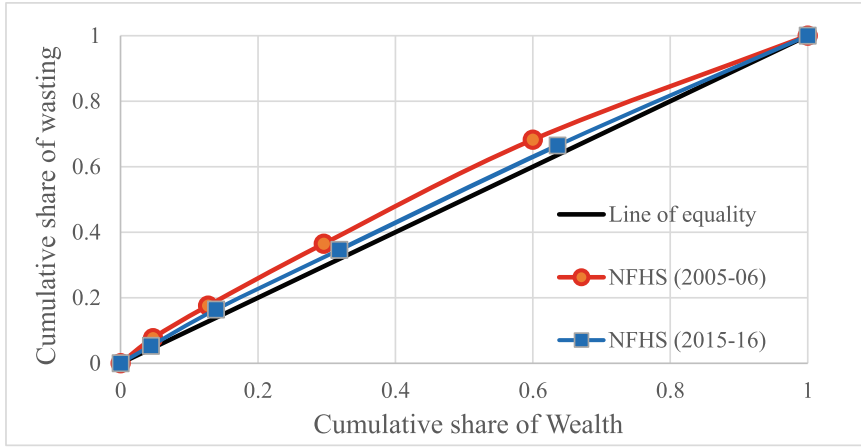

Concentration curve for wasting among children under five years in Urban India (2005-06 \& 2015-16)

Fig. 2 Concentration curves for stunting, underweight and wasting among children under five years in urban India, 2005-06 and 2015-16

inequality in underweight. The result found that healthseeking factors explained nearly one-fourth $(27.7 \%)$ of the inequality in underweight in 2005-06, but the same declined to nearly $14.4 \%$ in $2015-16$. The decline in the contribution of the place of delivery in explaining the inequality signifies the equitable access of institutional deliveries in urban areas among poor and non-poor. A study found that in India, the utilization of institutional delivery care has increased from $43 \%$ in 2004 to $83 \%$ in 2014 [21]. This increase in institutional delivery had helped in shrinking the gap of inequality in underweight, as explained by place of delivery.
Wasting is defined as $->2 \mathrm{SD}$ weight-for-height among children. It is a measure of current nutrition status, also known as acute undernutrition. The inequality in wasting among children has decreased, but the prevalence of wasting has increased. Around the world, wasting had reduced at a plodding pace over the last 40 years, but in countries like India and Sri Lanka, wasting has increased [39]. Maternal factors (44.4\%) were the highest contributory factors in explaining the inequality in wasting among children during 2005-06, but the contribution of maternal factors in inequality in wasting had declined significantly to $22.2 \%$ in $2015-16$. In previous 
Table 3 Estimates of decomposition analysis for contribution of various explanatory variables for stunting among urban children under five years in India, 2005-06 \& 2015-16

\begin{tabular}{|c|c|c|c|c|c|c|c|c|}
\hline \multirow[b]{2}{*}{ Variables } & \multicolumn{4}{|c|}{ NFHS 2005-06 } & \multicolumn{4}{|c|}{ NFHS 2015-16 } \\
\hline & Elasticity & $\mathrm{Cl}$ & $\begin{array}{l}\text { Absolute } \\
\text { contribution } \\
\text { to } \mathrm{Cl}\end{array}$ & $\begin{array}{l}\text { Percentage } \\
\text { Contribution }\end{array}$ & Elasticity & $\mathrm{Cl}$ & $\begin{array}{l}\text { Absolute } \\
\text { contribution } \\
\text { to } \mathrm{Cl}\end{array}$ & $\begin{array}{l}\text { Percentage } \\
\text { Contribution }\end{array}$ \\
\hline \multicolumn{9}{|l|}{ Mother factors } \\
\hline Age (years) & -0.061 & 0.019 & -0.001 & 2.3 & -0.067 & 0.025 & -0.002 & 5.5 \\
\hline Education & -0.055 & 0.173 & -0.010 & 19.1 & -0.086 & 0.094 & -0.008 & 26.6 \\
\hline Age at First Birth (years) & -0.110 & 0.045 & -0.005 & 9.9 & 0.019 & 0.023 & 0.000 & -1.5 \\
\hline Parity & 0.081 & -0.091 & -0.007 & 14.8 & 0.076 & -0.075 & -0.006 & 19.0 \\
\hline Anemia & -0.007 & -0.076 & 0.001 & -1.1 & 0.015 & -0.051 & -0.001 & 2.6 \\
\hline \multicolumn{9}{|l|}{ Socio-economic factors } \\
\hline Caste & -0.083 & 0.026 & -0.002 & 4.4 & -0.071 & 0.025 & -0.002 & 5.9 \\
\hline Religion & -0.008 & -0.003 & 0.000 & -0.1 & 0.003 & -0.002 & 0.000 & 0.0 \\
\hline \multicolumn{9}{|l|}{ Child factors } \\
\hline Age (months) & 0.094 & -0.005 & 0.000 & 0.9 & 0.023 & 0.001 & 0.000 & -0.1 \\
\hline Sex & -0.030 & -0.004 & 0.000 & -0.3 & -0.026 & -0.003 & 0.000 & -0.3 \\
\hline Anemia & 0.065 & -0.064 & -0.004 & 8.4 & 0.040 & -0.058 & -0.002 & 7.7 \\
\hline Diarrhea & 0.001 & -0.025 & 0.000 & 0.1 & 0.000 & -0.039 & 0.000 & 0.0 \\
\hline Birth weight & 0.011 & 0.098 & 0.001 & -2.2 & 0.012 & -0.027 & 0.000 & 1.1 \\
\hline Colostrum feeding & 0.001 & 0.079 & 0.000 & -0.2 & 0.002 & 0.009 & 0.000 & -0.1 \\
\hline \multicolumn{9}{|l|}{ Environmental factors } \\
\hline Source of drinking water & 0.035 & 0.013 & 0.000 & -0.9 & 0.010 & -0.002 & 0.000 & 0.1 \\
\hline Defecation & -0.085 & 0.066 & -0.006 & 11.4 & -0.094 & 0.046 & -0.004 & 14.3 \\
\hline Stool Disposal & 0.007 & -0.308 & -0.002 & 4.1 & 0.009 & -0.308 & -0.003 & 8.9 \\
\hline Regions of India & 0.045 & 0.014 & 0.001 & -1.3 & -0.026 & -0.002 & 0.000 & -0.2 \\
\hline \multicolumn{9}{|l|}{ Health seeking factors } \\
\hline Skilled birth attendant & 0.000 & 0.141 & 0.000 & -0.1 & -0.032 & 0.042 & -0.001 & 4.5 \\
\hline Place of delivery & -0.070 & 0.163 & -0.011 & 22.8 & -0.029 & 0.050 & -0.001 & 4.9 \\
\hline Full Immunization & -0.016 & 0.146 & -0.002 & 4.6 & 0.023 & 0.046 & 0.001 & -3.5 \\
\hline Full ANC & -0.004 & 0.360 & -0.001 & 3.2 & -0.007 & 0.208 & -0.001 & 4.5 \\
\hline Explained Cl & & & -0.050 & 100 & & & -0.030 & 100.00 \\
\hline Actual $\mathrm{Cl}$ & & & -0.186 & & & & -0.156 & \\
\hline Residual & & & -0.136 & & & & -0.126 & \\
\hline
\end{tabular}

studies, maternal factors were deemed as the contributory factors in explaining the inequalities in wasting among children aged below five years [23]. Nearly half of the inequality in wasting among children had been explained by open defecation (46.9\%) in 2015-16, citing the importance of sanitation. Since the weight-for-height is a measure of current nutritional status and is likely to be affected by small illnesses episodes and infectious diseases [23], the contribution of defecation in inequality in wasting among children is highly visible. Unavailability of toilet facilities within households promotes open defecation, and in turn, it facilitates water-borne diseases, which negatively affect the current health and nutrition status among children. Open defecation reinforces undernutrition (wasting) via increased susceptibility to infections and through reducing immunity [31].

\section{Strengths and limitations}

One of the strengths of the study is the considerable sample size for both the survey periods. This study explores the inequalities in stunting, underweight, and stunting among urban poor by employing survey data, which is 10 years apart, thus giving a clear picture of decadal change in economic inequality in stunting, underweight, and wasting among urban children. Decomposition allows our understanding of various factors 
Table 4 Estimates of decomposition analysis for contribution of various explanatory variables for underweight among urban children under five years in India, 2005-06 \& 2015-16

\begin{tabular}{|c|c|c|c|c|c|c|c|c|}
\hline \multirow[b]{2}{*}{ Variables } & \multicolumn{4}{|c|}{ NFHS 2005-06 } & \multicolumn{4}{|c|}{ NFHS 2015-16 } \\
\hline & Elasticity & $\mathrm{Cl}$ & $\begin{array}{l}\text { Absolute } \\
\text { contribution } \\
\text { to } \mathrm{Cl}\end{array}$ & $\begin{array}{l}\text { Percentage } \\
\text { Contribution }\end{array}$ & Elasticity & $\mathrm{Cl}$ & $\begin{array}{l}\text { Absolute } \\
\text { contribution } \\
\text { to } \mathrm{Cl}\end{array}$ & $\begin{array}{l}\text { Percentage } \\
\text { Contribution }\end{array}$ \\
\hline \multicolumn{9}{|l|}{ Mother factors } \\
\hline Age (years) & -0.043 & 0.019 & -0.001 & 1.8 & -0.072 & 0.025 & -0.002 & 5.96 \\
\hline Education & -0.078 & 0.173 & -0.013 & 28.8 & -0.081 & 0.094 & -0.008 & 25.44 \\
\hline Age at First Birth (years) & -0.067 & 0.045 & -0.003 & 6.4 & 0.004 & 0.023 & 0.000 & -0.34 \\
\hline Parity & 0.041 & -0.091 & -0.004 & 7.9 & 0.064 & -0.075 & -0.005 & 16.29 \\
\hline Anemia & 0.011 & -0.076 & -0.001 & 1.7 & 0.010 & -0.051 & -0.001 & 1.68 \\
\hline \multicolumn{9}{|l|}{ Socio-economic factors } \\
\hline Caste & -0.048 & 0.026 & -0.001 & 2.7 & -0.059 & 0.025 & -0.001 & 5.04 \\
\hline Religion & -0.030 & -0.003 & 0.000 & -0.2 & -0.005 & -0.002 & 0.000 & 0.00 \\
\hline \multicolumn{9}{|l|}{ Child factors } \\
\hline Age (months) & 0.079 & -0.005 & 0.000 & 0.8 & 0.059 & 0.001 & 0.000 & -0.25 \\
\hline Sex & -0.017 & -0.004 & 0.000 & -0.2 & -0.029 & -0.003 & 0.000 & -0.25 \\
\hline Anemia & 0.033 & -0.064 & -0.002 & 4.5 & 0.025 & -0.058 & -0.001 & 4.87 \\
\hline Diarrhea & 0.002 & -0.025 & 0.000 & 0.1 & 0.001 & -0.039 & 0.000 & 0.17 \\
\hline Birth weight & 0.015 & 0.098 & 0.001 & -3.2 & 0.019 & -0.027 & -0.001 & 1.68 \\
\hline Colostrum feeding & 0.003 & 0.079 & 0.000 & -0.5 & 0.002 & 0.009 & 0.000 & -0.08 \\
\hline \multicolumn{9}{|l|}{ Environmental factors } \\
\hline Source of drinking water & 0.038 & 0.013 & 0.000 & -1.0 & 0.033 & -0.002 & 0.000 & 0.17 \\
\hline Defecation & -0.119 & 0.066 & -0.008 & 16.9 & -0.112 & 0.046 & -0.005 & 17.46 \\
\hline Stool Disposal & 0.010 & -0.308 & -0.003 & 6.7 & 0.008 & -0.308 & -0.002 & 7.81 \\
\hline Regions of India & 0.028 & 0.014 & 0.000 & -0.9 & -0.006 & -0.002 & 0.000 & -0.08 \\
\hline \multicolumn{9}{|l|}{ Health seeking factors } \\
\hline Skilled birth attendant & -0.001 & 0.141 & 0.000 & 0.3 & -0.026 & 0.042 & -0.001 & 3.61 \\
\hline Place of delivery & -0.048 & 0.163 & -0.008 & 16.7 & -0.045 & 0.050 & -0.002 & 7.56 \\
\hline Full Immunization & -0.018 & 0.146 & -0.003 & 5.6 & 0.002 & 0.046 & 0.000 & -0.34 \\
\hline Full ANC & -0.006 & 0.360 & -0.002 & 5.0 & -0.005 & 0.208 & -0.001 & 3.61 \\
\hline Explained $\mathrm{Cl}$ & & & -0.047 & 100.00 & & & -0.030 & 100.00 \\
\hline Actual $\mathrm{Cl}$ & & & -0.213 & & & & -0.162 & \\
\hline Residual & & & -0.166 & & & & -0.132 & \\
\hline
\end{tabular}

contributing to the disparities inequality in stunting, underweight, and wasting among urban children. This study segregated the covariates of economic inequality into five categories; mother's factor, health-seeking factors, environmental factors, child factors, and socio-economic factors, thus highlighting the importance of particular covariate in explaining the inequality. The cross-sectional nature of data limits our knowledge about the causation accurately. Maternal factors used in this article may not be exclusively maternal physiological or maternal factors as such only, some of them are more of socio-economic nature (e.g. education). Educational status is commonly used as a proxy of socio-economic status.

\section{Conclusions}

The study made a reasonable attempt to describe the growth pattern among children below five along with the inequality in stunting, underweight, and wasting among children in urban India. Several important observations emerge from this study. First, during 2005-06 as well as 2015-16, maternal factors (specifically mother's education) were the highest contributory factors in explaining rich-poor inequality in stunting and underweight among urban children. Second, maternal factors were the most significant contributory factors in explaining the wasting among children during 2005-06, however environmental factors (specifically open defecation) 
Table 5 Estimates of decomposition analysis for contribution of various explanatory variables for wasting among urban children under five years in India, 2005-06 \& 2015-16

\begin{tabular}{|c|c|c|c|c|c|c|c|c|}
\hline \multirow[b]{2}{*}{ Variables } & \multicolumn{4}{|c|}{ NFHS 2005-06 } & \multicolumn{4}{|c|}{ NFHS 2015-16 } \\
\hline & Elasticity & $\mathrm{Cl}$ & $\begin{array}{l}\text { Absolute } \\
\text { contribution } \\
\text { to } \mathrm{Cl}\end{array}$ & $\begin{array}{l}\text { Percentage } \\
\text { Contribution }\end{array}$ & Elasticity & $\mathrm{Cl}$ & $\begin{array}{l}\text { Absolute } \\
\text { contribution } \\
\text { to } \mathrm{Cl}\end{array}$ & $\begin{array}{l}\text { Percentage } \\
\text { Contribution }\end{array}$ \\
\hline \multicolumn{9}{|l|}{ Mother factors } \\
\hline Age (Years) & -0.008 & 0.019 & 0.000 & 1.3 & -0.004 & 0.025 & 0.000 & 1.4 \\
\hline Education & -0.023 & 0.173 & -0.004 & 33.4 & -0.009 & 0.094 & -0.001 & 11.8 \\
\hline Age at First Birth (years) & 0.006 & 0.045 & 0.000 & -2.1 & -0.004 & 0.023 & 0.000 & 1.4 \\
\hline Parity & 0.013 & -0.091 & -0.001 & 9.9 & 0.006 & -0.075 & 0.000 & 6.6 \\
\hline Anemia & 0.003 & -0.076 & 0.000 & 1.9 & 0.002 & -0.051 & 0.000 & 1.0 \\
\hline \multicolumn{9}{|l|}{ Socio-economic factors } \\
\hline Caste & -0.034 & 0.026 & -0.001 & 7.6 & -0.009 & 0.025 & 0.000 & 3.1 \\
\hline Religion & -0.004 & -0.003 & 0.000 & 0.0 & -0.010 & -0.002 & 0.000 & -0.4 \\
\hline \multicolumn{9}{|l|}{ Child factors } \\
\hline Age (months) & -0.068 & -0.005 & 0.000 & -2.5 & -0.056 & 0.001 & 0.000 & 0.7 \\
\hline Sex & -0.027 & -0.004 & 0.000 & -1.1 & -0.023 & -0.003 & 0.000 & -0.7 \\
\hline Anemia & -0.006 & -0.064 & 0.000 & -3.0 & -0.008 & -0.058 & 0.000 & -6.6 \\
\hline Diarrhea & 0.003 & -0.025 & 0.000 & 0.4 & 0.001 & -0.039 & 0.000 & 0.7 \\
\hline Birth weight & 0.007 & 0.098 & 0.001 & -5.9 & 0.010 & -0.027 & 0.000 & 3.5 \\
\hline Colostrum feeding & 0.004 & 0.079 & 0.000 & -2.8 & 0.004 & 0.009 & 0.000 & -0.7 \\
\hline \multicolumn{9}{|l|}{ Environmental factors } \\
\hline Source of drinking water & 0.023 & 0.013 & 0.000 & -2.3 & 0.031 & -0.002 & 0.000 & 0.7 \\
\hline Defecation & -0.066 & 0.066 & -0.004 & 36.8 & -0.072 & 0.046 & -0.003 & 46.9 \\
\hline Stool Disposal & 0.002 & -0.308 & -0.001 & 3.8 & 0.002 & -0.308 & -0.001 & 8.0 \\
\hline Regions of India & 0.006 & 0.014 & 0.000 & -0.6 & 0.017 & -0.002 & 0.000 & 0.4 \\
\hline \multicolumn{9}{|l|}{ Health seeking factors } \\
\hline Skilled birth attendant & 0.011 & 0.141 & 0.002 & -12.7 & -0.001 & 0.042 & 0.000 & 0.4 \\
\hline Place of delivery & -0.004 & 0.163 & -0.001 & 5.3 & -0.006 & 0.050 & 0.000 & 3.8 \\
\hline Full Immunization & -0.022 & 0.146 & -0.003 & 26.4 & -0.025 & 0.046 & -0.001 & 16.0 \\
\hline Full ANC & -0.002 & 0.360 & -0.001 & 6.1 & -0.001 & 0.208 & 0.000 & 2.1 \\
\hline Explained $\mathrm{Cl}$ & & & -0.012 & 100.00 & & & -0.007 & 100.00 \\
\hline Actual $\mathrm{Cl}$ & & & -0.116 & & & & -0.045 & \\
\hline Residual & & & -0.104 & & & & -0.038 & \\
\hline
\end{tabular}

became the most significant contributory factors in explaining the rich-poor inequality in wasting among children during $2015-16$. Third, more than $85 \%$ of the inequality in stunting, underweight, and wasting among urban children was explained by maternal factors, environmental factors, and health-seeking factors. Fourth, growth faltering among children reaches its peak by the end of 2 years of age.

Rich-poor inequality in malnutrition calls out for the expedite policy interventions aimed at poverty reduction in urban areas. There is also a need to provide mass education regarding nutrition and health, along with focussing on the correlates that aim at improving mother's education. Environmental factors also promoted the inequality in stunting, wasting, and underweight in urban children; there is a need to focus the enigma of open defecation in India. After the launch of Swachh Bharat Mission in 2014, the government of India has focused a lot on building individual household latrines [6]. Despite having access to latrines, people prefer to defecate in open $[3,8,18,32]$. There is a need to promote the use of latrines among Indian masses. There is a need to bring a change in behavioural aspects and preferences of people to promote latrine use. Information, Education, and Communication (IEC) activities are encouraged to clamp down the economic inequality in stunting, 
underweight, and wasting among urban children. Since the cognitive and developmental deficiency resulting from malnutrition may significantly be irreversible after two years of age [7], it is being understood that the 'window of opportunity' for preventing malnutrition ends at age two years. It is therefore encouraged that policy-makers shall evenly target children for nutritional programs, with emphasis on children aged below two years.

All the nutrition-specific and nutrition-sensitive interventions in urban areas should be prioritized, focusing on urban poor, who are often clustered in low-income slums. Rich-poor inequality in child growth faltering calls out for integration and convergence of nutrition interventions with policy intervention aimed at poverty reduction in urban areas. There is also a need to expand the scope of the ICDS program to provide mass education regarding nutrition and health by making provisions of home visits primarily focusing at pregnant and lactating mothers.

\section{Supplementary Information}

The online version contains supplementary material available at https://doi. org/10.1186/s12889-020-09864-2.

Additional file 1: Figure-S1. Poor and non-poor differentials for growth patterns among children in urban India, 2005-06 and 2015-16. TableS1 Mean and standard error estimates for HAZ, WAZ and WHZ scores among children under 5 years in urban India, 2005-06. Table- S2 Mean and standard error estimates for HAZ, WAZ and WHZ scores among children under 5 years in urban India, 2015-16

\section{Abbreviations}

ANC: Ante Natal Care; BCG: Bacillus Calmette-Guerin; CC: Concentration Curve; Cl: Concentration Index; DPT: Diphtheria, Pertussis, and Tetanus; GHI: Global Hunger Index; HAZ: Height-for-Age Z score; ICDS: Integrated Child Development Services; IEC: Information, Education, and Communication; IFA: Iron Folic Acid; IIPS: International Institute for Population Sciences; NCHS: National Centre for Health Statistics; NFHS: National Family Health Survey; ODF: Open Defecation Free; SC: Schedule Caste; ST: Schedule Tribe; UNICEF: United Nations International Children's Emergency Fund; WAZ: Weight-for-Age Z score; WHO: World Health Organization; WHZ: Weight-for-Height Z score; Se: Standard error; SD: Standard deviation

\section{Acknowledgements}

Not applicable.

\section{Authors' contributions}

The concept was drafted by SKS; SS contributed to the analysis design, SKS and SS advised on the paper and assisted in paper conceptualization. SC and SS contributed in the comprehensive writing of the article. All authors read and approved the final manuscript.

\section{Author's information}

Dr. S.K Singh completed his PhD from Banaras Hindu University, Banaras, India. His area of interest is in Reproductive and Sexual Health. He is currently on the position of Professor in Department of Mathematical Demography and Statistics, International Institute for Population. He had over 200 publications in the domain of Nutrition and Reproductive and Sexual Health.

Shobhit Srivastava completed his M.Phil in Population studies and currently pursuing his PhD in Population studies from International Institute for
Population. His area of interest is Ageing and Mental Health issues among older adults.

Shekhar Chauhan completed his M. Phil in Population studies and currently pursuing his PhD in Population studies from International Institute for Population. His area of interest is public health issues in India.

\section{Funding}

Authors did not received any funding to carry out this research.

\section{Availability of data and materials}

The study utilises secondary source of data which is freely available in public domain through http://iipsindia.org.

\section{Ethics approval and consent to participate}

The data is freely available in public domain and survey agencies that conducted the field survey for the data collection have collected a prior consent from the respondent. Local ethics committee of International Institute for Population Sciences (IIPS), Mumbai, ruled that no formal ethics approval was required to carry out research from this data source.

\section{Consent for publication}

Not applicable.

\section{Competing interests}

The authors declare that they have no competing interests.

\section{Author details}

${ }^{1}$ Department of Mathematical Demography and Statistics, International Institute for Population Sciences, Mumbai, Maharashtra 400088, India. ${ }^{2}$ Department of Population Policies and Programmes, International Institute for Population Sciences, Mumbai, Maharashtra 400088, India.

Received: 8 June 2020 Accepted: 9 November 2020

Published online: 03 December 2020

\section{References}

1. Ali B, Chauhan S. Inequalities in the utilisation of maternal health care in rural India: Evidences from National Family Health Survey III \& IV. BMC Public Health. 2020;20(1):369. https://doi.org/10.1186/s12889-020-08480-4.

2. Almasian Kia A, Goodarzi S, Asadi H, Khosravi A, Rezapour A. A decomposition analysis of inequality in malnutrition among under five children in Iran: findings from multiple indicator demographic and health survey, 2010. Iran J Public Health. 2019;48(4):748-57. https://doi.org/10. 18502/ijph.v48i4.1009.

3. Banda K, Sarkar R, Gopal S, Govindarajan J, Harijan BB, Jeyakumar MB, Mitta P, Sadanala ME, Selwyn T, Suresh CR, Thomas VA, Devadason P, Kumar R, Selvapandian D, Kang G, Balraj V. Water handling, sanitation and defecation practices in rural southern India: a knowledge, attitudes and practices study. Trans R Soc Trop Med Hyg. 2007;101(11):1124-30. https://doi.org/10.1016/j. trstmh.2007.05.004.

4. Black, R. E., Allen, L. H., Bhutta, Z. A., Caulfield, L. E., de Onis, M., Ezzati, M., Mathers, C., \& Rivera, J. (2008). Maternal and child undernutrition: global and regional exposures and health consequences. In Lancet 371, 9608, 243-260 Elsevier. https://doi.org/10.1016/S0140-6736(07)61690-0.

5. Chauhan BG, Chauhan S, Chaurasia H. Decomposing the gap in child malnutrition between poor and non-poor in Sierra Leone. J Public Health (Germany). 2019;27(1):119-27. https://doi.org/10.1007/s10389-018-0924-6.

6. Chauhan S, Patel R, Bansod D. Are we ignoring the importance of sanitation while mourning the adverse pregnancy outcomes? Clinics in Mother and Child Health. 2020;17(2):1-3. https://doi.org/10.35248/2090-7214.20.17.346.

7. Checkley W, Epstein LD, Gilman RH, Cabrera L, Black RE. Effects of acute diarrhea on linear growth in Peruvian children. Am J Epidemiol. 2003;157(2): 166-75. https://doi.org/10.1093/aje/kwf179.

8. Coffey D, Gupta A, Hathi P, Khurana N, Spears D, Srivastav N, Vyas S Revealed preference for open defecation: evidence from a new survey in rural North India. In: Economic and Political Weekly (Vol. 49, issue 38); 2014.

9. Correia LL, EAC S, Sales Campos J, de Andrade FM, O, Machado MMT, Lindsay AC, Leite ÁJM, Rocha HAL, da Cunha AJLA. Prevalence and determinants of child undernutrition and stunting in semiarid region of Brazil. Revista de Saude Publica. 2014. https://doi.org/10.1590/S0034-8910. 2014048004828 
10. Deshpande A, Ramachandran R. Which Indian children are short and why? Social identity, Childhood Malnutrition and Cognitive Outcomes. Working Papers; 2020.

11. Fotso JC, Madise N, Baschieri A, Cleland J, Zulu E, Kavao Mutua M, Essendi $H$. Child growth in urban deprived settings: does household poverty status matter? At which stage of child development? Health Place. 2012;18(2):37584. https://doi.org/10.1016/j.healthplace.2011.12.003.

12. GHI. (2019). Global, regional, and National Trends - global hunger index peer-reviewed annual publication designed to comprehensively measure and track hunger at the global, regional, and country levels. Global Hunger Index. https://www.globalhungerindex.org/results.html.

13. GOI. (2013). Planning Commission, Government of India. In Planning commission, government of India. http://planningcommission.nic.in/sectors/ index.php?sectors=energy.

14. Headey D, Menon P, Nguyen P. The timing of growth faltering in India has changed significantly over 1992-2016, with variations in prenatal and postnatal improvement (P10-005-19). Curr Dev Nutrition. 2019; 3(Supplement_1). https://doi.org/10.1093/CDN/NZZ034.P10-005-19.

15. Holme AR, Blair PS, Emond AM. Psychosocial and educational outcomes of weight faltering in infancy in ALSPAC. BMJ Open. 2013;3(7):e002863. https:// doi.org/10.1136/bmjopen-2013-002863.

16. Humphrey, J. H., Mbuya, M. N. N., Ntozini, R., Moulton, L. H., Stoltzfus, R. J., Tavengwa, N. V., Mutasa, K., Majo, F., Mutasa, B., Mangwadu, G., Chasokela, C. M., Chigumira, A., Chasekwa, B., Smith, L. E., Tielsch, J. M., Jones, A. D., Manges, A. R., Maluccio, J. A., Prendergast, A. J., ... Makoni, T. (2019). Independent and combined effects of improved water, sanitation, and hygiene, and improved complementary feeding, on child stunting and anaemia in rural Zimbabwe: a cluster-randomised trial. Lancet Glob Health, 7(1), e132-e147. https://doi.org/10.1016/S2214-109X(18)30374-7.

17. IIPS, \& ICF. (2017). National Family Health Survey (NFHS-4), 2015-16: India. In International Institute for Population Sciences (IIPS) and ICF. kwm120 [pii]https://doi.org/10.1093/aje/kwm120.

18. Jenkins M, Freeman M, Routray P. Measuring the safety of excreta disposal behavior in India with the new safe san index: reliability, validity and utility. Int J Environ Res Public Health. 2014;11(8):8319-46. https://doi.org/10.3390/ ijerph110808319.

19. Jha R, Gaiha R, Sharma A. Poverty nutrition trap in rural India. SSRN Electron J. 2011. https://doi.org/10.2139/ssrn.695661.

20. Jiang Y, Su X, Wang C, Zhang L, Zhang X, Wang L, Cui Y. Prevalence and risk factors for stunting and severe stunting among children under three years old in mid-western rural areas of China. Child Care Health Dev. 2015; 41(1):45-51. https://doi.org/10.1111/cch.12148.

21. Joe W, Perkins JM, Kumar S, Rajpal S, Subramanian SV. Institutional delivery in India, 2004-14: Unravelling the equity-enhancing contributions of the public sector. Health Policy Plan. 2018. https://doi.org/10.1093/heapol/ czy029.

22. Khan J, Mohanty SK. Spatial heterogeneity and correlates of child malnutrition in districts of India. BMC Public Health. 2018;18(1):1-13. https:// doi.org/10.1186/s12889-018-5873-Z

23. Kumar A, Singh A. Decomposing the gap in childhood Undernutrition between poor and non-poor in urban India, 2005-06. PLoS One. 2013;8(5). https://doi.org/10.1371/journal.pone.0064972.

24. Liem S, Marta DRF, Panggabean, P. D. phil. H. Sanitation behavior and risk of stunting: understanding the discourse of a public service announcement. Jurnal The Messenger. 2019;11(2):168. https://doi.org/10.26623/ themessenger.v11i2.1317.

25. Mamidi RS, Shidhaye P, Radhakrishna KV, Babu JJ, Reddy PS. Pattern of growth faltering and recovery in under-5 children in India using WHO growth standards - A study on first and third national family health survey. Indian Pediatr. 2011;48(11):855-60. https://doi.org/10.1007/ s13312-011-0139-1.

26. Nguyen P, Scott S, Avula R, Agarwal A, Menon P, Headey D, Ruel M. Urbanization and the double burden: trends and inequalities in under- and over-nutrition by residence and wealth among 1.22 million Indian children, women and men over 10 years (P10-078-19). Curr Dev Nutr. 2019; 3(Supplement_1). https://doi.org/10.1093/CDN/NZZ034.P10-078-19.

27. Nie P, Rammohan A, Gwozdz W, Sousa-Poza A. Changes in child nutrition in India: A decomposition approach. Int J Environ Res Public Health. 2019; 16(10):1815. https://doi.org/10.3390/ijerph16101815.

28. Pal A, Pari AK, Sinha A, Dhara PC. Prevalence of undernutrition and associated factors: A cross-sectional study among rural adolescents in West
Bengal, India. International Journal of Pediatrics and Adolescent Medicine. 2017;4(1):9-18. https://doi.org/10.1016/j.jpam.2016.08.009.

29. Prakash M, Jain K. Inequalities among malnourished children in India A decomposition analysis from 1992-2006. In: International Journal of Social Economics (Vol. 43, issue 6, pp. 643-659). Emerald Group publishing Itd; 2016. https://doi.org/10.1108/IJSE-01-2014-0006.

30. Ramani G, Heckert J, Go A, Iruhiriye E, Niyongira O. Stories of Change: Rwanda: Understanding the drivers of stunting reduction ... - Ramani, Gayathri V., Heckert, Jessica, Go, Ara, Iruhiriye, Elyse, Niyongira, Emmanuel, Olney, Deanna K. - Google Books. International Food Policy Research Institute; 2019.

31. Robert C, Von Medeazza G. Sanitation and stunting in India: Undernutrition's blind spot. Econ Polit Wkly. 2013:15-8.

32. Routray P, Schmidt WP, Boisson S, Clasen T, Jenkins MW. Socio-cultural and behavioural factors constraining latrine adoption in rural coastal Odisha: an exploratory qualitative study global health. BMC Public Health. 2015;15(1): 880. https://doi.org/10.1186/s12889-015-2206-3.

33. Sahu SK, Kumar SG, Bhat BV, Premarajan KC, Sarkar S, Roy G, Joseph N. Malnutrition among under-five children in India and strategies for control. In: Journal of Natural Science, Biology and Medicine (Vol. 6, issue 1, pp. 1823). Medknow publications; 2015. https://doi.org/10.4103/0976-9668.149072.

34. Shrimpton R, Victora CG, de Onis M, Lima RC, Blössner M, Clugston G. Worldwide timing of growth faltering: implications for nutritional interventions. Pediatrics. 2001;107(5):e75-5. https://doi.org/10.1542/peds.107.5.e75.

35. Singh SK, Srivastava S, Upadhyay AK. Socio-economicic inequality in malnutrition among children in India: an analysis of 640 districts from National Family Health Survey (2015-16). Int J Equity Health. 2019;18(1):1-9. https://doi.org/10.1186/s12939-019-1093-0.

36. Srivastava A, Mahmood SE, Srivastava PM, Shrotriya VP, Kumar B. Nutritional status of school-age children - A scenario of urban slums in India. Archives of Public Health. 2012;70(1):8. https://doi.org/10.1186/0778-7367-70-8.

37. Surya AV, Sharma R. Understanding the Impact of Open Defaecation on Child Diarrhoea and Nutrition Indicators. Journal of Health Management. 2019;21(4):487-96. https://doi.org/10.1177/0972063419884446.

38. UNICEF. Stop stunting in South Asia: A common narrative on maternal and child nutrition. UNICEF South Asia Strategy. 2015:2014-7 https://www. unicef.org/rosa/reports/stop-stunting-south-asia-common-narrativematernal-and-child-nutrition.

39. UNICEF, World Health Organization, \& The World Bank. (2012). UNICEFWHO- World Bank. Joint Child Malnutrition Estimates: Levels \& trends in child malnutrition. Africa.

40. Victora CG, De Onis M, Hallal PC, Blössner M, Shrimpton R. Worldwide timing of growth faltering: revisiting implications for interventions. Pediatrics. 2010;125(3):e473-80. https://doi.org/10.1542/peds.2009-1519.

41. Wagstaff A. Socio-economicic inequalities in child mortality: comparisons across nine developing countries. In: Bulletin of the World Health Organization; 2000. https://doi.org/10.1590/S0042-96862000000100003.

42. Walker S, Susan M, Christine A, Simonoff E, Grantham-McGregor S. Early childhood stunting is associated with poor psychological functioning in late adolescence and effects are reduced by psychosocial stimulation. J Nutr. 2007:137(11):2464-9. https://doi.org/10.1093/JN.

43. Waterlow, J. C. (1973). Note on the assessment and classification of proteinenergy malnutrition in children. Lancet, 302(7820), 87-89. https://doi.org/10. 1016/S0140-6736(73)93276-5.

44. West J, Syafiq A, Crookston B, Bennett C, Hasan MR, Dearden K, Linehan M, Hall C, Torres S. Stunting-related knowledge: exploring sources of and factors associated with accessing stunting-related knowledge among mothers in rural Indonesia. Health. 2018;10(09):1250-60. https://doi.org/10. 4236/health.2018.109096.

45. World Health Organization. Interpretation guide nutrition landscape information system (NLIS). In Who. 2010. https://doi.org/10.1159/000362780. Interpretation.

46. Yadav A, Ladusingh L, Gayawan E. Does a geographical context explain regional variation in child malnutrition in India? Journal of Public Health (Germany). 2015;23(5):277-87. https://doi.org/10.1007/s10389-015-0677-4.

47. Yenneti K, Wei YD, Chen W. The urbanization of poverty in India: Spatiotemporal disparities in consumption expenditures. Geogr Rev. 2017;107(2): 360-83. https://doi.org/10.1111/j.1931-0846.2016.12167.x.

\section{Publisher's Note}

Springer Nature remains neutral with regard to jurisdictional claims in published maps and institutional affiliations. 